\title{
SOBRE A LARVA DE CHARADRELLA MALLACOPHAGA LOPES (DIPTERA, MUSCIDAE)
}

\author{
Márcia Souto Couri ${ }^{1}$
}

\begin{abstract}
ON THE LARVA OF CHARAdRELlA MallaCophagA LOPES (DipterA, MUSCIDAE). Descriptions and illustrations are made of the second larval instar of the larviparous species Charadrella mallacophaga.

KEY WORDS. Diptera, Muscidae, Charadrella mallacophaga, larval morphology
\end{abstract}

A condição larvípara encontrada em Charadrella mallacophaga Lopes, 1938 não é incomum entre os Reinwardtinae. Registros desta condição já foram feitos para espécies de Cyrtoneurina Giglio-Tos, 1893 e Polietina Schnabl \& Dziedzichi, 1911, (SNYDER 1954; SKIDMORE 1985; CoURI \& CARVAlHo no prelo). Segundo SKIDMORE (1985: 47), a viviparidade é comum nesta subfamília.

ALBUQUERQUE (1947) e CARVALHO (1980) mencionaram a associação de C. mallacophaga com moluscos gastrópodes (Thaumastus taumaysi Ferussac, 1822 e Streptasis sp.), na qual as fêmeas depositam suas larvas nos moluscos, causandoIhes a morte. AlBUQUERQUE (1947) apresentou ainda descrição e ilustração do adulto e da larva do terceiro ínstar. SKIDMORE (1985) redescreveu e ilustrou a larva de terceiro ínstar.

A larva do segundo instar é caracterizada neste trabalho, e são feitos comentários com relação às diferenças morfológicas entre o segundo e terceiro ínstares.

O material estudado pertence à coleção do Museu Nacional, Rio de Janeiro.

\section{Charadrella mallacophaga Lopes, 1938}

Figs 1-6

Descrição. Larva do segundo ínstar: Comprimento total: 4,0-4,5mm. Aspecto geral como na figura 1. Segmento cefálico com espinhos no terço médio, próximos à porção anterior do esqueleto céfalo-faringeano, distribuídos como nas figuras 1 e 2. Primeiro e segundo segmentos torácicos sem espinhos. Terceiro segmento torácico e segmentos abdominais I-V com fileiras de espinhos na metade ventral (Figs 1, 5). Segmento abdominal VI com um anel completo de espinhos na margem inferior. Espiráculo posterior localizado distalmente, no segmento abdominal VI, com duas aberturas incompletamente divididas (Figs 1, 6). Espiráculo anterior não observado. Esqueleto céfalo-faringeano com gancho bucal denteado (Figs 3,6).

1) Museu Nacional, Universidade Federal do Rio de Janeiro. Quinta da Boa Vista, 20940-040 Rio de Janeiro, Rio de Janeiro, Brasil. Bolsista do CNPq. 
Comentários. As diferenças morfológicas entre as larvas de segundo e terceiro ínstares estão principalmente relacionadas com: distribuição de espinhos nos segmentos, número e forma das fendas espiraculares posteriores e esqueleto céfalo-faringeano, especialmente na mandíbula que é denteada no segundo ínstar.

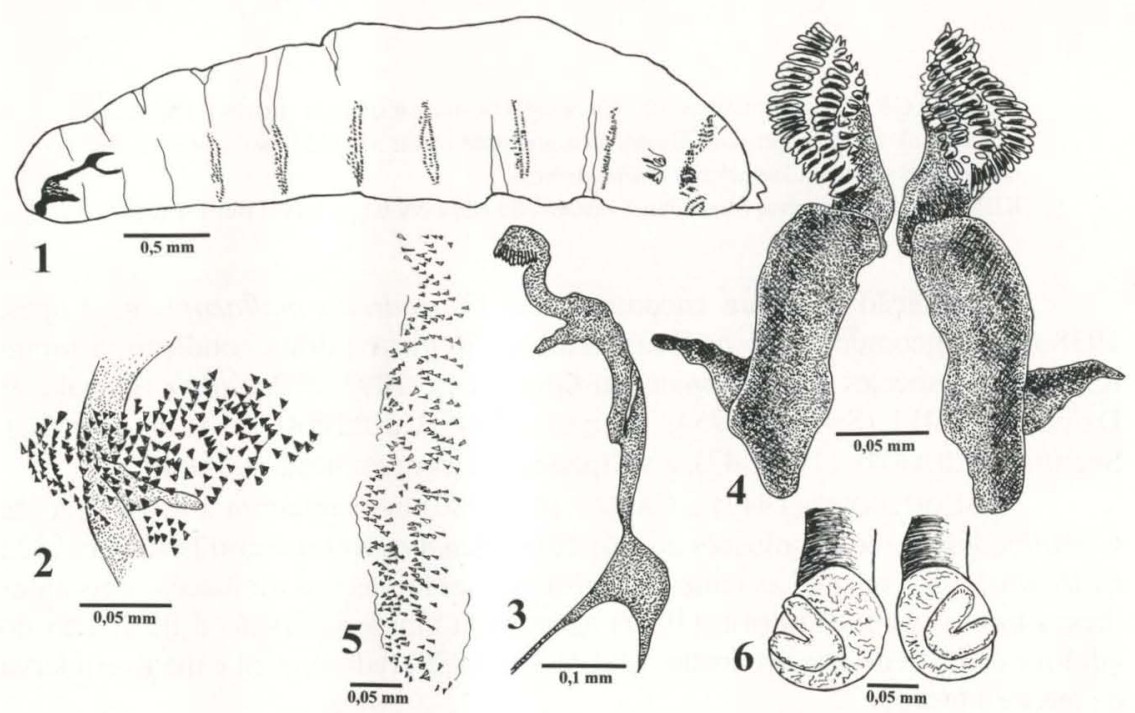

(Figs 1-6). Charadrella mallacophaga. (1) Aspecto geral da larva do segundo instar; (2) detalhe da distribuição dos espinhos do segmento cefálico; (3) esqueleto céfalo-faringeano; (4) detalhe do esqueleto céfalo-faringeano; (5) detalhe da distribuição dos espinhos no segmento abdominal; (6) espiráculo posterior.

\section{REFERÊNCIAS BIBLIOGRÁFICAS}

Albuquerque, D. DE O. 1947. Contribuição ao conhecimento de Charadrella mallacophaga Lopes, 1938 (Muscidae, Diptera). Rev. Ent. 18 (1-2): 101-112.

Carvalho, C.J.B. DE. 1980. Estudo sobre Charadrella Wulp, 1896 (Diptera, Muscidae, Cyrtoneurininae). Dusenia 12 (2): 57-62.

Couri, M.S. \& C.J.B. DE CARVAlHo. (no prelo). Duas novas espécies de Polietina

Schnabl \& Dziedzicki, 1911 (Diptera, Muscidae) do Brasil. Revta bras. Zool..

SNYDER, F.M. 1954. A revison of Cyrtoneurina Giglio-Tos, with notes on related

genera (Diptera, Muscidae). Bull. Amer. Mus. Nat. Hist. 103 (6): 421-461, 63 figs.

SKIDMORE, P. 1985. The biology of the Muscidae of world. Dordrecht Junk Publishers, XIV+550p.

Recebido em 30.X.1995; aceito em 07.XI.1996. 